\title{
Seven years of growth hormone (GH) replacement improves quality of life in hypopituitary patients with adult-onset GH deficiency
}

\author{
Mariam Elbornsson, Alexandra Horvath, Galina Götherström, \\ Bengt-Åke Bengtsson, Gudmundur Johannsson and Johan Svensson \\ Department of Endocrinology, Institute of Medicine, Sahlgrenska Academy, University of Gothenburg, \\ Göteborg, Sweden
}

Correspondence should be addressed to J Svensson

Email

johan.svensson@medic.gu.se

\begin{abstract}
Objective: Few studies have determined the effects of long-term growth hormone (GH) replacement on quality of life (QoL). This study investigated the effects of 7 years of GH replacement on QoL.

Design: A prospective, single-center, open-label study of 95 adults (mean age 52.8 years; 46 men) with adult-onset GH deficiency (GHD).

Methods: QoL was measured using Quality of Life-Assessment for Growth Hormone Deficiency in Adults (QoL-AGHDA) and Psychological General Well-Being (PGWB) scores.

Results: The GH dose was gradually increased from $0.13 \mathrm{mg} /$ day to $0.42 \mathrm{mg} /$ day. IGF-I SD score increased from -1.49 at baseline to 0.35 at study end. The GH replacement induced sustained improvements in total QoL-AGHDA and PGWB scores. GHD women had a more marked improvement in total QoL-AGHDA score than GHD men after 5 and 7 years. Most of the improvement in QoL was seen during the first year, but there was a small further improvement also after one year as measured using QoL-AGHDA. All QoL-AGHDA dimensions improved, but the improvement in memory and concentration as well as tenseness occurred later than that of other dimensions. Correlation analysis demonstrated that the patients with the lowest baseline QoL had the greatest improvement in QoL.

Conclusions: Seven years of GH replacement improved QoL with the most marked improvements in GHD women and in patients with low baseline QoL. Most, but not all, of the improvement in QoL was seen during the first year. Some QoL-AGHDA dimensions (memory and concentration, tenseness) responded at a slower rate than other dimensions.
\end{abstract}

\section{Introduction}

Adult hypopituitarism with untreated growth hormone (GH) deficiency (GHD) is associated with altered body composition, low bone mass, decreased exercise capacity, impaired cardiovascular risk factors and increased cardiovascular mortality $(1,2)$. Furthermore, although there is heterogeneity in the degree of impairment $(3,4)$, most adult hypopituitary patients with GHD not receiving GH replacement have compromised quality of life (QoL) (4). The patients are more socially isolated than healthy
(C) 2017 European Society of Endocrinology Printed in Great Britain controls (5), and suffer from tiredness, lack of initiative and concentration, irritability, reduced physical and mental drive, decreased vitality and difficulties in coping with stressful situations compared to healthy controls $(4,6,7)$.

Several placebo-controlled studies have demonstrated improved QoL in GHD adults in response to $\mathrm{GH}$ replacement $(8,9,10,11)$. In a placebo-controlled study not using any disease-specific QoL questionnaire, QoL was

Published by Bioscientifica Ltd. 
normal at baseline and GH replacement did not improve QoL (12). In a meta-analysis of open GH treatment trials in adults, QoL improved with a small effect size and wellbeing with a medium effect size (13). In a systematic review, 11 of the 16 reviewed studies showed an improvement in at least one subsection of the used QoL assessment tool (14). The increase in QoL has most often been inversely related to the baseline reduction in QoL, suggesting that patients with more severely impaired QoL at baseline have a greater response to GH replacement $(4,15)$. Furthermore, most of the improvement in QoL is seen during the first year of GH replacement (16), although the results of some studies suggest that an additional increase in QoL can occur also after one year of therapy (17).

Long-term studies demonstrate that GH replacement improves most of the features of adult $\operatorname{GHD}(1,2)$. However, in terms of QoL, few long-term studies have been performed. In a 10-year study, 10 GHD adults who had continued GH replacement had higher QoL compared to GHD adults who had discontinued the therapy as determined using the Nottingham Health Profile (NHP) (18). In 17 GHD patients who received continuous GH replacement for 9 years, QoL improved as determined using NHP and Psychological General Well-Being (PGWB) questionnaires (19). Four studies based on postmarketing surveillance programs, the Pfizer International Metabolic Database (KIMS, $n=2)(20,21)$, and the Hypopituitary Control and Complications Study (HypoCCS, $n=2)(16$, 22), showed sustained improvements in QoL for 4-10 years using the Quality of Life-Assessment for Growth Hormone Deficiency in Adults (QoL-AGHDA) questionnaire or the Questions on Life Satisfaction-Hypopituitarism (QLS-H) questionnaire although dropout rates were relatively high. Therefore, in a systematic review of longterm studies, further studies were recommended in terms of the long-term effect of GH replacement on QoL (23).

In this single-center prospective study, we aimed to determine the effect of 7 years of GH replacement on QoL in 95 well-characterized hypopituitary patients. All patients had adult-onset hypopituitary disease and verified GHD. QoL was assessed using the QoL-AGHDA and PGWB questionnaires.

\section{Subjects and methods}

\section{Patients}

In this open prospective study of the effect of adult GH replacement on QoL, 95 GHD adults (46 men) with a mean age 52.8 (s.E.M. 1.6; range 20-76) years at study start (men: mean 53.1 (s.E.M. 2.4) years and women: 52.5 (2.0) years) were included from 1995 to 2006. The patients had adult-onset GHD and all had known pituitary disease or other anterior pituitary hormonal deficiencies. Pituitary tumors and/or their treatments were the main cause of the pituitary deficiencies (Table 1), and the majority of the patients had multiple anterior pituitary hormonal deficiencies (Table 1). Seventy of the GHD adults had received therapy directed to the pituitary (pituitary surgery $(n=51)$, both surgery and irradiation $(n=12)$ and irradiation alone $(n=7))$. In 94 of the patients, the diagnosis of GHD was based on a peak $\mathrm{GH}<3 \mu \mathrm{g} / \mathrm{L}$ during a stimulation test (insulin $(n=84)$ or GHRH $(n=10))$. In one patient, previously treated with pituitary surgery and irradiation and with one additional anterior pituitary deficiency, the diagnosis was based on a 24-h GH profile (sampling every $30 \mathrm{~min}$ ).

Four patients died during the study period due to pulmonary cancer, chronic obstructive lung disease, peritonitis and warfarin-related hemorrhagic stroke. Fifteen patients discontinued GH replacement (patient's wish/lack of compliance $(n=9)$, brain metastases $(n=1)$, colon cancer $(n=1)$, lung cancer $(n=1)$, prostate cancer $(n=1)$, progress of pituitary tumor $(n=1)$ and cognitive impairment $(n=1))$. Four patients were lost to follow-up because they moved to other cities or abroad. The number of patients remaining in the study was 92 at 1 year (97\%), 81 at 3 years (85\%), 76 at 5 years (80\%) and 72 at 7 years

Table 1 Causes of pituitary deficiency and type of pituitary deficiency in the study population of 95 hypopituitary patients with adult-onset GHD.

\begin{tabular}{|c|c|c|c|}
\hline & Men $(n)$ & Women $(n)$ & Total $(n)$ \\
\hline \multicolumn{4}{|l|}{ Cause of pituitary deficiency } \\
\hline $\begin{array}{l}\text { Non-secreting pituitary } \\
\text { adenoma }\end{array}$ & 25 & 19 & 44 \\
\hline Secreting pituitary adenoma\# & 5 & 12 & 17 \\
\hline Craniopharyngioma & 3 & 3 & 6 \\
\hline Empty sella & 1 & 1 & 2 \\
\hline Idiopathic & 8 & 6 & 14 \\
\hline Other pathology ${ }^{\S}$ & 4 & 8 & 12 \\
\hline Total & 46 & 49 & 95 \\
\hline \multicolumn{4}{|l|}{ Type of deficiency } \\
\hline Isolated GHD & 3 & 2 & 5 \\
\hline 1. Additional deficiency & 12 & 12 & 24 \\
\hline 2. Additional deficiencies & 11 & 17 & 28 \\
\hline 3. Additional deficiencies & 20 & 18 & 38 \\
\hline Diabetes insipidus & 8 & 7 & 15 \\
\hline $\begin{array}{l}\text { \#Contains prolactinoma }(n=6) \text {, prev } \\
\text { previous acromegaly }(n=5) .{ }^{\S} \text { Contai } \\
(n=3) \text {, meningioma }(n=2) \text {, septo-op } \\
(n=1) \text {, hamartoma }(n=1) \text {, Sheehan's } \\
(n=1) \text {, sarcoidosis }(n=1) \text { and trauma }\end{array}$ & $\begin{array}{l}\text { s previous } \\
\text { ic dysplasi } \\
\text { syndrome } \\
\text { tic brain in }\end{array}$ & $\begin{array}{l}\text { s disease }(n= \\
\text { ranial irradiat } \\
(n=1) \text {, hypop } \\
n=1) \text {, pituitar } \\
\text { rry }(n=1) \text {. }\end{array}$ & $\begin{array}{l}\text { and } \\
\text { on therapy } \\
\text { sitis } \\
\text { apoplexy }\end{array}$ \\
\hline
\end{tabular}


(76\%). However, according to the intention-to-treat strategy used, all patients were retained in the statistical analyses as the last values obtained before the patients were discontinued were carried forward in the analyses.

Ten patients were treated with antidepressants during the study period (first year $(n=2)$, years $1-3(n=4)$, and remaining part of the study $(n=4))$. For these ten patients, according to the intention-to-treat strategy used, the last QoL values obtained before they received antidepressant therapy were carried forward in the statistical analyses.

\section{Substitution of additional anterior pituitary hormone deficiencies}

When required, patients received replacement therapy with glucocorticoids, thyroid hormone, gonadal steroids and desmopressin. Doses of glucocorticoids (cortisone acetate or hydrocortisone) were calculated as hydrocortisone equivalent doses (20 mg hydrocortisone equals $25 \mathrm{mg}$ cortisone acetate) based on the antiinflammatory effects (24). In patients with glucocorticoid substitution, the baseline dose of $20.0 \mathrm{mg}$ (s.E.M. $1.3 \mathrm{mg}$; hydrocortisone equivalents) was reduced after 1 year to $19.2(1.2) \mathrm{mg}(P<0.05)$, whereas the dose after 7 years was statistically similar as that at baseline $(19.0(1.0) \mathrm{mg}$, $P=0.08)$. The dose of thyroxine replacement in $\mathrm{TSH}$ deficient patients was increased from 79 (5) $\mu \mathrm{g}$ at baseline to $89(5) \mu \mathrm{g}$ after 1 year $(P<0.001)$ and $113(4) \mu \mathrm{g}$ after 7 years $(P<0.001)$. In men as well as in women, the number of patients that received treatment with gonadal hormones was similar at all the time points of the study. In men, 33 patients received testosterone treatment at baseline as well as after 1 year and 7 years. In women, 21 patients received estrogen treatment at baseline as well as after 1 year, whereas 19 patients received estrogen treatment after 7 years.

\section{Ethical considerations}

Informed consent was obtained from all patients. The study was approved by the Regional Ethical Review Board at the University of Gothenburg. The study was conducted according to the Declaration of Helsinki.

\section{Study protocol}

This was a prospective, open-label study. All patients started with a low individualized GH dose, which was gradually increased with the aim of normalizing serum
IGF-I concentration and body composition in each patient. Dose titration and safety monitoring including laboratory examinations were performed every third month during the first year, every sixth month during the second year, and then yearly. No effort was made to influence the patients' physical activity level during the study period.

\section{Quality of life}

Quality of life (QoL) was assessed at baseline and after 1 year (mean 1.03, s.E.M. 0.01, range 0.90-1.59 years after the baseline visit), 3 years (3.05, 0.02, 2.713.69 years), 5 years $(5.09,0.02,4.70-5.66$ years $)$, and 7 years $(7.09,0.03,6.72-7.73$ years $)$. QoL was determined using questionnaires (Quality of Life-Assessment for Growth Hormone Deficiency in Adults (QoL-AGHDA) and Psychological General Well-Being (PGWB) index (25)). QoL-AGHDA is a disease-based instrument that has specifically been developed for adults with GHD, detecting deficits in needs achievement in affected areas $(26,27,28)$. It consists of 25 items, and each item evokes a 'yes' or a 'no' answer. Each 'yes' answer is assigned a score of 1 , and the sum of the number of 'yes' answers (range 0-25) is used as a measure of QoL with a high QoL-AGHDA score indicating a poor QoL $(20,29,30)$. Furthermore, we divided QoL-AGHDA into five states (dimensions): memory and concentration (6 items; score range: 0-6), tiredness ( 7 items; 0-7), tenseness (3 items; $0-3)$, social isolation (5 items; 0-5), and self-confidence (4 items; 0-4) (20).

The PGWB index was developed as a subjective measurement of the patient's well-being or distress (25). The questionnaire consists of 22 items. The scoring for each item is $0-5$, with 0 being the most negative option and 5 the most positive. This gives a total score range of 0-110, with a low PGWB score denoting a poor QoL. The PGWB index is divided into six dimensions: anxiety (5 items; score range 0-25), depressed mood (3 items; 0-15), positive well-being (4 items: 0-20), self-control (3 items; $0-15$ ), general health (3 items; 0-15), and vitality (4 items; 0-20), thus reflecting the patient's experienced QoL.

In terms of total QoL-AGHDA score, we compared our values with those in a Swedish reference population described previously (20). QoL-AGHDA questionnaires were sent out in 2004 to a random sample $(n=3005)$ drawn from the population permanently registered in Sweden, aged 18-85 years (20). Responses were received from 1945 subjects (response rate, 65\%), and QoLAGHDA score was available for 1682 individuals (56\%) 
(20). The mean age of the total reference population was 48.3 (s.E.M. 0.4) years (men: 48.9 (0.5) years and women 47.7 (0.5) years) (20).

\section{Biochemical analysis}

Serum IGF-I concentration, until June 2004, was determined by a hydrochloric acid-ethanol extraction radioimmunoassay (RIA) (Nichols Institute Diagnostics, San Juan Capistrano, CA, USA). Inter-assay and intraassay CVs were $5.4 \%$ and $6.9 \%$, respectively, at a mean serum IGF-I level of $126 \mu \mathrm{g} / \mathrm{L}$, and $4.6 \%$ and $4.7 \%$, respectively, at mean serum IGF-I level of $327 \mu \mathrm{g} / \mathrm{L}$. From June 2004 to August 2006, serum IGF-I concentration was determined using a chemiluminescence immunoassay (Nichols Advantage; Nichols Institute Diagnostics) (31). From September 2006, serum IGF-I level was determined using an automated chemiluminescent assay system (IMMULITE 2500, Diagnostic Products Corp., Los Angeles, CA, USA). The WHO NIBSC 1st IRR 87/518 standard was used for calibration throughout the study period. The individual serum IGF-I values were compared with age- and sex-adjusted values obtained from a reference population (32), and the individual IGF-I SD scores were then calculated (33).

\section{Statistical methods}

The descriptive statistical results are presented as the mean and s.E.M. For all variables, within-group differences were calculated using the Friedman test, with all data obtained from all time points. Post hoc analysis was performed using the Wilcoxon test. Gender differences were calculated by comparing the changes from baseline at the given time point using the Mann-Whitney $U$-test. Correlations were sought using the Spearman rank order correlation test. Effect sizes (Cohen's $d$ ) were calculated as the difference between scores divided by the pooled standard deviation of the two evaluations (baseline and study end) (34). An effect size of $d=0.2-0.5$ was considered as a small effect, $d=0.5-0.8$ as a medium effect and $d>0.8$ as a large effect. All analyses were performed according to the intentionto-treat principle (using the carry forward principle). A two-tailed $P$-value $<0.05$ was considered significant.

\section{Results}

\section{Dose of GH and IGF-1 SD score}

The dose of $\mathrm{GH}$ increased from $0.13 \mathrm{mg} /$ day (the dose prescribed at the baseline visit) to $0.42 \mathrm{mg} /$ day at study end. IGF-I SD score increased but was within the normal physiological range $( \pm 2 \mathrm{SD})$ throughout the study period (Table 2).

\section{QoL-AGHDA}

Seven years of GH replacement improved QoL as measured using total QoL-AGHDA score with a small effect size on the margin to a moderate effect size (Fig. 1A and Table 3). Furthermore, all the five QoL-AGHDA dimensions (memory and concentration, tiredness, tenseness, social isolation and self-confidence) decreased, suggesting improved QoL (Table 3). The main improvement was seen during the first year, but a small further improvement after 1 year was observed for total QoL-AGHDA score and the QoL-AGHDA dimension social isolation (Table 3). Memory and concentration as well as tenseness responded slower than other QoL-AGHDA dimensions with a significant increase first after 3 years but with a gradual improvement between years 1 and 7 (Table 3).

Table 2 Dose of GH, serum IGF-I concentration, and IGF-I SD score during 7 years of GH replacement therapy in hypopituitary patients with adult-onset GHD (baseline, $n=95 ; 1$ year, $n=92 ; 3$ years, $n=81 ; 5$ years, $n=76$; and 7 years, $n=72$ ). All results are shown as mean (S.E.M.). The statistical analyses are based on the Friedman test followed by post hoc analysis using the Wilcoxon test. According to the intention-to-treat strategy used, all patients were retained in the statistical analyses as the last value obtained before the patients were discontinued was carried forward in the analyses.

\begin{tabular}{|c|c|c|c|c|c|c|}
\hline & Baseline & 1 year & 3 years & 5 years & 7 years & $\boldsymbol{P}$-Value (1-7 years) \\
\hline $\begin{array}{l}\text { Dose of GH (mg/ } \\
\text { day) }\end{array}$ & $0.13(0.01)$ & $0.38(0.01) * * *$ & $0.42(0.01) * * *$ & $0.42(0.02) * * *$ & $0.42(0.02) * * *$ & $<0.01$ \\
\hline $\begin{array}{l}\text { Serum IGF-I } \\
(\mu \mathrm{g} / \mathrm{L})\end{array}$ & $104(8)$ & $226(13) * * *$ & $216(11) * * *$ & $200(11) * * *$ & $180(10) * * *$ & $<0.001$ \\
\hline IGF-I SD score & $-1.49(0.15)$ & $0.97(0.25) * * *$ & $0.87(0.19) * * *$ & $0.65(0.21) * * *$ & $0.35(0.18) * * *$ & 0.06 \\
\hline
\end{tabular}

$P$-Values (1-7 years) denote the post-hoc $P$-values between the 7-year and the 1-year values.

$* * * P<0.001$ vs baseline. 
A

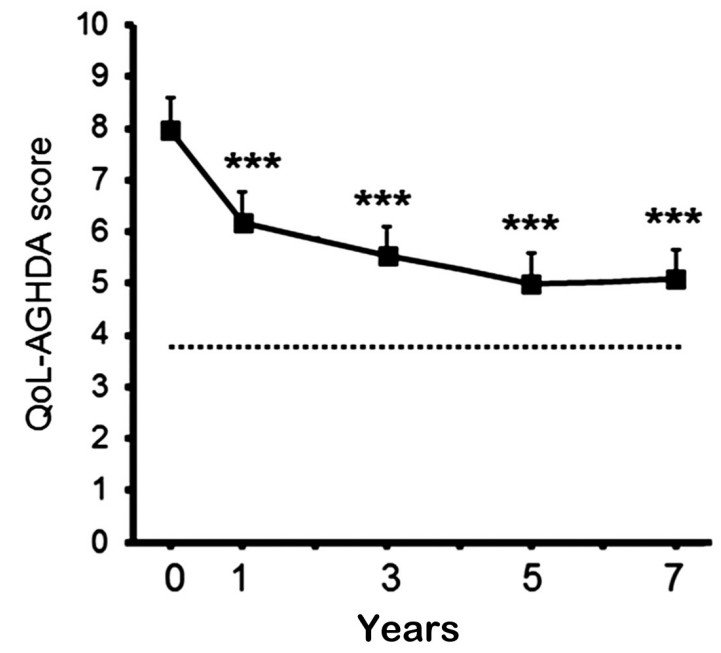

B

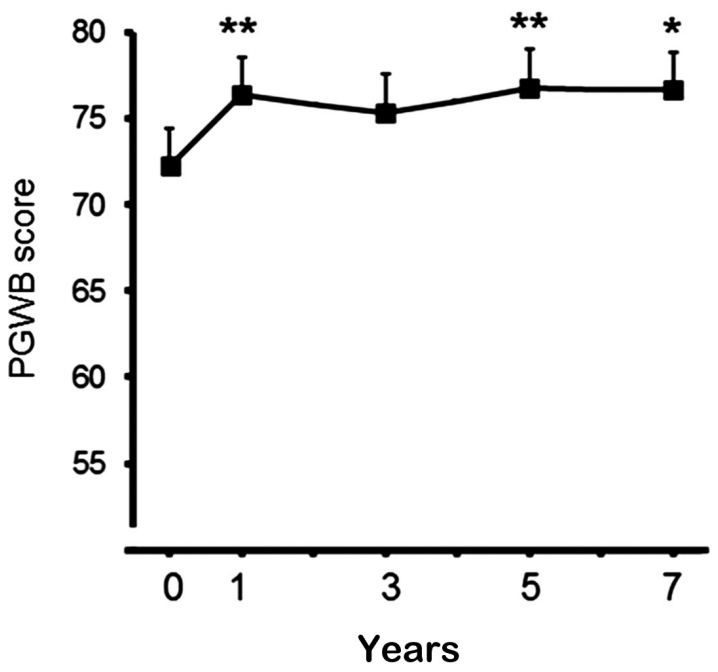

Figure 1

Quality of life (QoL) in hypopituitary patients with adult-onset growth hormone $(\mathrm{GH})$ deficiency during 7 years of $\mathrm{GH}$ replacement (baseline, $n=95$; 1 year, $n=92 ; 3$ years, $n=81$; 5 years, $n=76$; and 7 years, $n=72$ ). (A) Total QoL-AGHDA score decreased and (B) total PGWB score increased, suggesting a maintained improvement in QoL. The vertical bars indicate the S.E.M. for the mean values shown. The statistical analyses were based on the Friedman test followed by post hoc analysis using the Wilcoxon test. According to the intention-to-treat strategy used, all patients were retained in the statistical analyses as the last value obtained before the patients discontinued was carried forward in the analyses. The dotted line in $(A)$ represents the mean QoL-AGHDA score of 3.8 in a reference population in Sweden $(n=1682)$ with a mean age of 48.3 (0.4) years (20). ${ }^{*} P<0.05,{ }^{*} P<0.05, * * * P<0.001$ (vs baseline).

\section{PGWB index}

Total PGWB score was increased after 7 years with a small effect size (Fig. 1B and Table 4). The six PGWB dimensions (anxiety, depressed mood, positive well-being, self-control, general health and vitality) improved to a less marked extent than QoL-AGHDA dimensions (Table 4). Only selfcontrol was significantly increased after 7 years compared to baseline (Table 4). In addition, there was a transient increase in depressed mood. No PGWB dimension increased further between 1 and 7 years (Table 4).

\section{Gender differences in QoL}

The dose of GH prescribed at the first visit was $0.13 \mathrm{mg} /$ day in both genders, but after that, GHD men received a lower dose than GHD women. At study end, the mean dose was $0.38 \mathrm{mg} /$ day in men and $0.44 \mathrm{mg} /$ day in women. Men had a larger increase in IGF-I SD score during the first years of GH replacement but not at study end. In men, the mean IGF-1 SD score was -1.30 (s.E.M. 0.22) at baseline, 1.21 (0.30) after 3 years, and $0.27(0.29)$ after 7 years. In women, the corresponding IGF-1 SD score values were -1.68 (0.20), $0.54(0.22)$ and $0.43(0.21)$.

Total QoL-AGHDA score as well as all QoL-AGHDA dimensions were statistically similar in men and women at baseline and study end (total QoL-AGHDA: $P=0.34$ and $P=0.67$, respectively) (Table 5). However, after 5 and 7 years, the change from baseline in total QoL-AGHDA score and the QoL-AHGDA dimension memory and concentration was significantly larger in women than in men (Table 5). The response to treatment was similar in both genders in all other QoL-AGHDA scores (Table 5).

Total PGWB score and all PGWB dimensions were similar in both genders at baseline (total PGWB: men, 73.1 (3.3) and women, 71.5 (2.9); $P=0.49$ ) and at study end (total PGWB: men, 75.3 (3.4) and women, 78.0 (2.9); $P=0.85$ ). There were no significant gender differences in the change in total PGWB score or any PGWB dimension during the study (data not shown). After 7 years, total PGWB score had increased by 2.2 (2.5) and 6.5 (2.7) score units in men and women, respectively $(P=0.21)$.

\section{Total QoL-AGHDA score in comparison with a reference population}

In a previously published reference population from Sweden $(n=1682)$, total QoL-AGHDA scores were 3.8 
Table 3 Total QoL-AGHDA score and QoL-AGHDA dimensions during 7 years of GH replacement therapy in hypopituitary patients with adult-onset GHD (baseline, $n=95 ; 1$ year, $n=92 ; 3$ years, $n=81 ; 5$ years, $n=76$; and 7 years, $n=72$ ). A lower score indicates a better quality of life. After each variable name, the maximum score range of the variable is given. All results are shown as mean (S.E.M.). The statistical analyses are based on the Friedman test followed by post hoc analysis using the Wilcoxon test. According to the intention-to-treat strategy used, all patients were retained in the statistical analyses as the last value obtained before the patients were discontinued was carried forward in the analyses.

\begin{tabular}{|c|c|c|c|c|c|c|c|c|}
\hline & Baseline & 1 year & 3 years & 5 years & 7 years & $\begin{array}{c}P \text {-Value } \\
\text { (1-7 years) }\end{array}$ & $\begin{array}{c}\text { Change } \\
\text { (baseline-7 years) }\end{array}$ & $\begin{array}{c}\text { Effect size } \\
\text { ( } d \text { value) } \\
\text { (baseline-7 years) }\end{array}$ \\
\hline $\begin{array}{l}\text { Total QoL-AGHDA } \\
\text { score }(0-25)\end{array}$ & $8.0(0.6)$ & $6.2(0.6) * * *$ & $5.5(0.6) * * *$ & $5.0(0.6) * * *$ & $5.1(0.6) * * *$ & 0.02 & $-2.9(0.5)$ & 0.49 \\
\hline \multicolumn{9}{|c|}{ QoL-AGHDA dimensions } \\
\hline $\begin{array}{l}\text { Memory and } \\
\text { concentration } \\
(0-6)\end{array}$ & $1.9(0.2)$ & $1.8(0.2)$ & $1.5(0.2) * *$ & $1.4(0.2) * *$ & $1.4(0.2) * *$ & $<0.01$ & $-0.5(0.2)$ & 0.28 \\
\hline Tiredness (0-7) & $3.2(0.2)$ & $2.2(0.2) * * *$ & $2.1(0.2) * * *$ & $2.0(0.2) * * *$ & $2.2(0.2) * * *$ & 0.97 & $-1.1(0.2)$ & 0.45 \\
\hline Tenseness $(0-3)$ & $1.1(0.1)$ & $1.0(0.1)$ & $0.9(0.1)^{* *}$ & $0.8(0.1) * * *$ & $0.7(0.1) * * *$ & $<0.01$ & $-0.4(0.1)$ & 0.43 \\
\hline $\begin{array}{l}\text { Social isolation } \\
(0-5)\end{array}$ & $0.9(0.1)$ & $0.7(0.1)^{* *}$ & $0.6(0.1) * * *$ & $0.5(0.1) * * *$ & $0.5(0.1) * * *$ & 0.03 & $-0.4(0.1)$ & 0.41 \\
\hline $\begin{array}{l}\text { Self-confidence } \\
(0-4)\end{array}$ & $0.7(0.1)$ & $0.5(0.1) * *$ & $0.4(0.1) * *$ & $0.3(0.1) * * *$ & $0.3(0.1) * * *$ & 0.12 & $-0.3(0.1)$ & 0.36 \\
\hline
\end{tabular}

$P$-values (1-7 years) denote the post hoc $P$-values between the 7-year and the 1 -year values.

$* * P<0.01 ; * * * P<0.001$ vs baseline.

(0.1), $3.5(0.2)$ and $4.2(0.2)$ in the total study sample, men and women, respectively (20). In comparison, the mean QoL-AGHDA scores in our study population of 8.0 at baseline and 5.1 at study end were 4.2 and 1.3 score points higher, respectively, than that in the reference population (Fig. 1A). In GHD men, the corresponding total QoL-AGDA scores of 7.6 and 5.5 were 4.1 and 2.0 score points higher, respectively, than that in reference men. In GHD women, the corresponding scores of 8.3 and 4.6 were 4.1 and 0.4 score points higher than those in reference women.

\section{Low baseline QoL correlates with larger improvement in QoL}

At baseline, total QoL-AGHDA or PGWB score did not correlate with age, serum IGF-I or IGF-I SD score (data not shown). Furthermore, the change in total QoL-AGHDA or PGWB score did not correlate with the change in serum IGF-I or IGF-I SD score (data not shown). However, baseline QoL-AGHDA score as well as baseline PGWB score correlated negatively with the change in the same variable after 7 years $(r=-0.44, P<0.001$ and $r=-0.42$, $P<0.001)$. This means that the GHD patients with the lowest QoL at baseline had the largest improvement in QoL in response to 7 years of GH replacement. Similar negative correlations between the baseline value and the change in the same variable were seen for all
QoL-AGHDA dimensions (memory and concentration, $r=-0.43$; tiredness, $r=-0.46$; tenseness, $r=-0.60$; social isolation, $r=-0.68$; self-confidence, $r=-0.74$; all $P<0.001$ ). Furthermore, for all PGWB dimensions, the baseline value and the change in the same variable correlated negatively (all $P<0.001$, data not shown).

\section{Sensitivity analyses}

Ten patients were treated with antidepressants but according to the intention-to-treat strategy used, the last valid QoL values before the patients were treated with antidepressants were carried forward to the later time points in the statistical analyses. There was no major change in the statistical results if all values were included in the analyses or if these patients were totally excluded from the analyses (data not shown). Furthermore, if the 23 patients who did not complete the 7 years of GH replacement were excluded from the analyses, the results were approximately similar (total QoL-AGHDA score and all QoL-AGHDA dimensions as well as total PGWB score and the PGWB dimension selfcontrol were still significantly improved after 7 years compared to baseline). Finally, if all patients with changes in their replacement doses of glucocorticoids and/or thyroxine were excluded from the analyses, the PGWB dimension self-control, total QoL-AGHDA score and the QoL-AGHDA dimensions, memory and 
Table 4 Total PGWB score and PGWB dimensions during 7 years of GH replacement in hypopituitary patients with adult-onset GHD (baseline, $n=95$; 1 year, $n=92 ; 3$ years, $n=81 ; 5$ years, $n=76$; and 7 years, $n=72$ ). A higher PGWB score indicates a better quality of life. After each variable name, the maximum score range of the variable is given. All results are shown as mean (S.E.M.). The statistical analyses are based on the Friedman test followed by post hoc analysis using the Wilcoxon test. According to the intention-to-treat strategy used, all patients were retained in the statistical analyses as the last value obtained before the patients were discontinued was carried forward in the analyses.

\begin{tabular}{|c|c|c|c|c|c|c|c|c|}
\hline & Baseline & 1 year & 3 years & 5 years & 7 years & $\begin{array}{c}P \text {-Value } \\
\text { (1-7 years) }\end{array}$ & $\begin{array}{c}\text { Change } \\
\text { (baseline-7 years) }\end{array}$ & $\begin{array}{c}\text { Effect size } \\
(d \text { value }) \\
\text { (baseline-7 years) }\end{array}$ \\
\hline $\begin{array}{l}\text { Total PGWB } \\
\text { score }(0-110)\end{array}$ & $72.2(2.2)$ & $76.4(2.2) * *$ & $75.3(2.3)$ & $76.8(2.3) * *$ & $76.7(2.2)^{*}$ & 0.94 & $4.4(1.9)$ & 0.22 \\
\hline \multicolumn{9}{|c|}{ PGWB dimensions } \\
\hline $\begin{array}{r}\text { Anxiety } \\
(0-25)\end{array}$ & $18.0(0.6)$ & $18.8(0.5)$ & $18.5(0.6)$ & $18.8(0.5)$ & $19.1(0.5)$ & 0.43 & $1.1(0.5)$ & 0.23 \\
\hline $\begin{array}{l}\text { Depressed } \\
\text { mood } \\
(0-15)\end{array}$ & $11.8(0.3)$ & $12.3(0.3)$ & $12.4(0.3)$ & $12.4(0.4)$ * & $12.4(0.3)$ & 0.7 & $0.5(0.3)$ & 0.17 \\
\hline $\begin{array}{l}\text { Positive } \\
\text { well-being } \\
(0-20)\end{array}$ & $11.0(0.4)$ & $11.3(0.4)$ & $11.3(0.5)$ & $11.5(0.4)$ & $11.4(0.5)$ & 0.89 & $0.4(0.4)$ & 0.09 \\
\hline $\begin{array}{l}\text { Self-control } \\
(0-15)\end{array}$ & $10.9(0.4)$ & $11.9(0.4)$ ** & $11.7(0.4) * *$ & $12.0(0.4)^{* * *}$ & $12.2(0.3) * * *$ & 0.12 & $1.4(0.4)$ & 0.4 \\
\hline $\begin{array}{c}\text { General } \\
\text { health } \\
(0-15)\end{array}$ & $10.5(0.3)$ & $10.6(0.4)$ & $10.4(0.4)$ & $10.7(0.4)$ & $10.3(0.4)$ & 0.3 & $-0.3(0.3)$ & 0.08 \\
\hline $\begin{array}{l}\text { Vitality } \\
(0-20)\end{array}$ & $10.0(0.5)$ & $11.3(0.5)$ & $11.2(0.5)$ & $11.3(0.5)$ & $11.2(0.5)$ & 0.58 & $1.2(0.4)$ & 0.27 \\
\hline
\end{tabular}

$P$-Values (1-7 years) denote the post hoc $P$-values between the 7-year and the 1-year values. $* P<0.05 ; * * P<0.01 ; * * * P<0.001$ vs baseline.

concentration, tiredness, tenseness and self-confidence, remained improved after 7 years compared to baseline, whereas the improvements in total PGWB score and the QoL-AGHDA dimension social isolation lost significance $(P=0.23$ and $P=0.07$, respectively).

\section{Discussion}

In this single-center study, 7 years of GH replacement improved QoL in hypopituitary patients with adult-onset GHD as measured using the QoL-AGHDA and PGWB questionnaires. Most of the improvement was seen during the first year, but as measured using QoL-AGHDA, there was a small further improvement in QoL between years 1 and 7. All QoL-AGHDA dimensions improved although memory and concentration as well as tenseness responded later than other QoL-AGHDA dimensions. In terms of PGWB dimensions, only self-control was significantly improved after 7 years compared to baseline. Furthermore, the increase in QoL-AGHDA score was more marked in GHD women than in GHD men after 5 and 7 years. Correlation analysis showed that the patients with the lowest baseline QoL had the most marked improvement in QoL.
The main objective of the present study was to study the effect of long-term GH replacement on QoL in hypopituitary patients with adult-onset GHD. Previous studies showing improved QoL in response to GH replacement for 4-10 years have been performed in small number of patients ( $n=10$ and $n=17$, respectively) who received continued GH therapy $(18,19)$, or in large postmarketing surveillance programs with relatively high dropout rates $(16,20,21,22)$. In a systematic review, further studies regarding the long-term effect of GH replacement on QoL were recommended, especially studies including control groups (23). Although our study did not include a control group, we believe that our study adds information regarding the long-term efficacy of $\mathrm{GH}$ replacement in terms of QoL.

All the included patients received individualized GH replacement from the beginning of the study, which resulted in physiological increases in serum IGF-I concentration (IGF-I SD score values within \pm 2 s.D.). This individualized $\mathrm{GH}$ dosing resulted in a higher dose of GH in women, which is in line with previous results that women may be less sensitive to GH replacement in terms of serum IGF-I concentration and therefore need a higher dose $(1,2,15)$. Several, often relatively early, 
Table 5 Total QoL-AGHDA score and QoL-AGHDA dimensions during 7 years of GH replacement therapy in male ( $n=46)$ and female $(n=49)$ hypopituitary patients with adult-onset GHD. A lower score indicates a better quality of life. After each variable name, the maximum score range of the variable is given. All results are shown as mean (s.E.M.). Within-group differences were calculated using the Friedman test followed by post hoc analysis using the Wilcoxon test. Between-group differences were evaluated by comparing the changes from baseline at the given time point using the Mann-Whitney $U$-test. According to the intention-to-treat strategy used, all patients were retained in the statistical analyses as the last value obtained before the patients were discontinued was carried forward in the analyses.

\begin{tabular}{|c|c|c|c|c|c|c|c|c|}
\hline & Baseline & 1 year & 3 years & 5 years & 7 years & $\begin{array}{l}\text { P-Value } \\
\text { (1-7 years) }\end{array}$ & $\begin{array}{c}\text { Change } \\
\text { (Baseline-7 years) }\end{array}$ & $\begin{array}{c}\text { Effect size } \\
\text { ( } d \text { value) } \\
\text { (Baseline-7 years) }\end{array}$ \\
\hline \multicolumn{9}{|c|}{ Total QoL-AGHDA score (0-25) } \\
\hline Men & $7.6(1.0)$ & $6.0(0.9) *$ & $5.7(0.9) * *$ & $5.3(1.0) * *, \S$ & $5.5(0.9) * *$, & 0.49 & $-2.1(0.7)$ & 0.31 \\
\hline Women & $8.3(0.7)$ & $6.3(0.8) * *$ & $5.4(0.6) * * *$ & $4.7(0.7) * * *$ & $4.6(0.7) * * *$ & 0.02 & $-3.7(0.7)$ & 0.74 \\
\hline \multicolumn{9}{|c|}{ QoL-AGHDA dimensions } \\
\hline \multicolumn{9}{|c|}{ Memory and concentration (0-6) } \\
\hline Men & $1.7(0.3)$ & $1.7(0.3)$ & $1.5(0.3)$ & $1.6(0.3)^{\S \S}$ & $1.5(0.3)^{\S}$ & 0.31 & $-0.2(0.2)$ & 0.10 \\
\hline Women & $2.1(0.2)$ & $1.9(0.3)$ & $1.5(0.2) *$ & $1.3(0.2) * *$ & $1.2(0.2) * * *$ & $<0.01$ & $-0.8(0.2)$ & 0.52 \\
\hline \multicolumn{9}{|c|}{ Tiredness (0-7) } \\
\hline Men & $2.8(0.3)$ & $2.1(0.3)^{*}$ & $1.9(0.3) * *$ & $1.8(0.3) * *$ & $2.2(0.3)$ & 0.46 & $-0.7(0.3)$ & 0.29 \\
\hline Women & $3.6(0.3)$ & $2.4(0.3) * * *$ & $2.3(0.3) * * *$ & $2.2(0.3) * * *$ & $2.2(0.4) * * *$ & 0.35 & $-1.5(0.3)$ & 0.61 \\
\hline \multicolumn{9}{|c|}{ Tenseness (0-3) } \\
\hline Men & $1.2(0.2)$ & $0.9(0.2)$ & $0.8(0.1)^{*}$ & $0.8(0.2)^{*}$ & $0.8(0.2) * *$ & 0.30 & $-0.3(0.1)$ & 0.31 \\
\hline Women & $1.1(0.2)$ & $1.0(0.2)$ & $0.9(0.2)$ & $0.7(0.1)^{*}$ & $0.6(0.1) * *$ & $<0.01$ & $-0.5(0.2)$ & 0.55 \\
\hline \multicolumn{9}{|c|}{ Social isolation (0-5) } \\
\hline Men & $1.0(0.2)$ & $0.8(0.1) * *$ & $0.7(0.1) * * *$ & $0.7(0.2) * * *$ & $0.6(0.1) * * *$ & 0.03 & $-0.4(0.2)$ & 0.37 \\
\hline Women & $0.8(0.2)$ & $0.7(0.2) * *$ & $0.5(0.1) * * *$ & $0.3(0.1) * * *$ & $0.4(0.1) * * *$ & 0.03 & $-0.4(0.2)$ & 0.44 \\
\hline \multicolumn{9}{|c|}{ Self-confidence (0-4) } \\
\hline Men & $0.8(0.2)$ & $0.6(0.2) * *$ & $0.6(0.1)^{* *}$ & $0.4(0.1) * * *$ & $0.5(0.1) * * *$ & 0.12 & $-0.4(0.1)$ & 0.33 \\
\hline Women & $0.5(0.1)$ & $0.4(0.1) * *$ & $0.2(0.1) * *$ & $0.1(0.1) * * *$ & $0.2(0.1) * * *$ & 0.12 & $-0.3(0.1)$ & 0.42 \\
\hline
\end{tabular}

${ }^{*} P<0.05 ;{ }^{*} P<0.01 ;{ }^{* *} P<0.001$ vs baseline; ${ }^{\S} P<0.05 ;{ }^{\S} P P<0.01$ men vs women.

studies showed that GHD women had larger impairments of baseline QoL and more marked increases in QoL in response to GH replacement compared to men (35). We observed a non-significant tendency to more severely impaired baseline QoL in GHD women, and after 5 and 7 years of GH replacement, the improvement in total QoL-AGHDA score was more marked in women than in men. Therefore, GH replacement might induce a larger improvement in QoL in GHD women also if the dose of $\mathrm{GH}$ is titrated on an individual basis. Furthermore, in the total study population, most but not all of the increase in QoL occurred during the first year. Post hoc analysis showed a further improvement in QoL also after 1 year as measured using QoL-AGHDA total score, whereas PWBG total score did not increase further after 1 year. The results therefore concur with those of previous studies $(16,17)$ and suggest that the main part of the improvement in QoL is seen during the first year of GH replacement whereas a marginal improvement in QoL can also occur after 1 year.

All QoL-AGHDA dimensions were improved by 7 years of GH replacement. Tiredness and self-confidence were increased from 1 year and onwards, without any significant further improvement after 1 year. Social isolation was increased after 1 year but still improved between years 1 and 7. In contrast, memory and concentration as well as tenseness were increased compared to baseline first after 3 years, but there was a significant improvement in these dimensions between 1 and 7 years. Few studies have evaluated the effect of longterm GH replacement on QoL-AGHDA dimensions. In a previous KIMS study, memory and concentration as well as tiredness were the most severely impaired QoL-AGHDA dimensions compared to population-based normative data at baseline and possibly, therefore, these dimensions were the latest to be approximately normalized (20). Thus, both the present study and the previous study (20) have identified memory and concentration as a QoL-AGHDA dimension that increase/normalize slower than other QoL-AGHDA dimensions in response to GH therapy. Furthermore, because we observed an increase in memory and concentration only in GHD women, gender-specific effects could be of importance for the late increase in this QoL-AGHDA dimension. Our results of dimensionspecific and gender-specific effects of long-term GH 
replacement might be of importance for clinical practice, but the results need to be confirmed in further studies including control groups and the underlying mechanisms require more detailed investigation.

The increase in total PGWB score was less marked than the increase in total QoL-AGHDA score at study end. Moreover, only one PGWB dimension (self-control) was improved after 7 years, whereas other dimensions were statistically unaltered compared to baseline. QoL-AGHDA was developed to detect QoL deficits specifically in adult GHD $(26,27,28)$, and it is therefore not surprising that PGWB is not as sensitive as QoL-AGHDA for the specific QoL profile in adult GHD.

In a previous meta-analysis of open $\mathrm{GH}$ treatment trials in adults, QoL improved with a small effect size and well-being with a medium effect size (13). In previous long-term studies of the effects of GH replacement for 4-10 years on QoL, Cohen's $d$ effect sizes were not presented $(16,18,19,20,21,22)$. In our study, the 7-year GH replacement increased total QoL-AGHDA score with a small effect size on the limit to a moderate effect size $(d=0.49)$. Most QoL-AGHDA dimensions as well as total PGWB score had increased after 7 years with a small effect size. In support of a more marked increase in QoL in GHD women, the 7-year GH replacement increased total QoLAGHDA with a small effect size in GHD men and with a moderate effect size in GHD women.

The change in all QoL-AGHDA and PGWB scores (total scores as well as dimensions) correlated negatively with the change in the same variable. This means that the GHD patients with the lowest baseline QoL at baseline had the largest improvement in QoL in response to 7 years of GH replacement. It cannot be excluded that these inverse correlations between baseline QoL and the change in QoL were due to regression to the mean. The results of studies with shorter duration than the present one suggest that GH replacement increases QoL in adult GHD patients with impaired baseline QoL $(8,9,10,11)$, but not in GHD adults with nearly normal QoL at baseline (12). However, GH therapy in adult hypopituitarism is a replacement therapy restoring a pathological state, and it might not be expected that GH will affect QoL in patients not experiencing impaired QoL as a consequence of the hypopituitarism. In the present study, the mean total QoL-AGHDA score of 8.0 at baseline and 5.1 at study end were both higher than the mean total QoL-AGHDA score of 3.8 in a Swedish reference population (20). Probably, the impaired QoL at baseline was a prerequisite for the observed improvement in QoL in response to the 7 years of GH replacement.
In the present study, the mean replacement doses of glucocorticoids and thyroxine was reduced and increased, respectively, during the study period. In contrast, the number of patients receiving gonadal steroids did not significantly change in GHD men or GHD women. However, most of the improvements of QoL also remained after exclusion of patients that changed their dose of glucocorticoids and/or thyroid hormones during the study period (only the increases in total PGWB score and the QoL-AGHDA dimension social isolation lost significance). Therefore, most of the improvement in QoL was probably produced by the GH replacement.

In addition to the changes in the doses of additional anterior pituitary hormones, the present study has several limitations such as the open-label design and the lack of a control group. However, for ethical reasons, we could not include a control group of GHD patients for an extended time period without GH replacement. Furthermore, we cannot exclude selection biases in the recruitment of patients, and the level of physical activity, which could potentially affect QoL, was not recorded. However, no effort was made to influence the patients' physical activity level during the study period. Another limitation is that the IGF-I assay changed two times. Although the WHO NIBSC 1st IRR 87/518 standard was used for calibration throughout the study period, it cannot be excluded that the changes in IGF-I assay could have influenced the results of the IGF-I measurements. Ten patients were treated with antidepressants but according to the intention-to-treat strategy used, the last QoL values before the patients were treated with antidepressants were carried forward in the statistical analyses. There was no major change in the statistical results if all values were included in the analyses or if these patients were totally excluded from the analyses. Finally, if the 23 patients who did not complete the 7 years of GH replacement were excluded from the analyses, the results were approximately similar.

In conclusion, in an open-label, prospective, singlecenter study of well-characterized hypopituitary patients, we demonstrate that the improvement in QoL observed in short-term trials is also maintained during 7 years of GH replacement. The improvement in QoL was most pronounced in GHD women and in patients with low baseline QoL. Most of the improvement was seen during the first year, although, as measured using QoL-AGHDA, there was a small further improvement in QoL between years 1 and 7. Some QoL-AGHDA dimensions (memory and concentration, tenseness) responded at a slower rate than other dimensions. Further studies including control 
groups are needed to determine gender-specific and dimension-specific effects of long-term GH replacement as well as the underlying mechanisms.

\section{Declaration of interest}

G J has received lecture fees from Pfizer, Novo Nordisk, Merck Serono and Eli Lilly and is a member of the SAB for KIMS Pfizer. B-Å B has previously received a research grant from Pharmacia/Pfizer. The other authors have nothing to declare.

Funding

This work was supported by the ALF/LUA research grant in Gothenburg (ALFGBG-146841).

\section{Acknowledgements}

We thank Salmir Nasic, biostatistician, Skaraborg Central Hospital, Skövde, Sweden, for statistical advice. We are indebted to all the staff at the Department of Endocrinology for their skillful technical support.

\section{References}

1 Drake W, Howell S, Monson J \& Shalet S. Optimizing GH therapy in adults and children. Endocrine Reviews 200122 425-450. (doi:10.1210/edrv.22.4.0438)

2 Nilsson A, Svensson J \& Johannsson G. Management of growth hormone deficiency in adults. Growth Hormone and IGF Research 2007 17 441-462. (doi:10.1016/j.ghir.2007.05.005)

3 Holmes S \& Shalet S. Factors influencing the desire for long-term growth hormone replacement in adults. Clinical Endocrinology 1995 43 151-157. (doi:10.1111/j.1365-2265.1995.tb01909.x)

4 Woodhouse L, Mukherjee A, Shalet S \& Ezzat S. The influence of growth hormone status on physical impairments, functional limitations, and health-related quality of life in adults. Endocrine Reviews 200627 287-317. (doi:10.1210/er.2004-0022)

5 Holmer H, Svensson J, Rylander L, Johannsson G, Rosén T, Bengtsson B-Å, Thorén M, Höybye C, Degerblad M, Bramnert M et al. Psychosocial health and levels of employment in 851 hypopituitary Swedish patients on long-term GH therapy. Psychoneuroendocrinology 201338 842-852. (doi:10.1016/j. psyneuen.2012.09.008)

6 McGauley G. Quality of life assessment before and after growth hormone treatment in adults with growth hormone deficiency. Acta Paediatrica Scandinavica. Supplement 1989356 70-72. (doi:10.1111/j.1651-2227.1989.tb11249.x)

7 Rosén T, Wirén L, Wilhelmsen L, Wiklund I \& Bengtsson B-Å. Decreased psychological well-being in adult patients with growth hormone deficiency. Clinical Endocrinology 199440 111-116. (doi:10.1111/j.1365-2265.1994.tb02452.x)

8 Bengtsson B-Å, Edén S, Lönn L, Kvist H, Stokland A, Lindstedt G, Bosaeus I, Tölli J, Sjöström L \& Isaksson O. Treatment of adults with growth hormone $(\mathrm{GH})$ deficiency with recombinant human $\mathrm{GH}$. Journal of Clinical Endocrinology and Metabolism 199376 309-317. (doi:10.1210/jc.76.2.309)

9 Mård G, Lundin K, Borg G, Jonsson B \& Lindberg A. Growth hormone replacement therapy in adult hypopituitary patients with growth hormone deficiency: combined data from 12 European placebo-controlled clinical trials. Endocrinology and Metabolism 19941 (Supplement A) 43-49.

10 Burman P, Broman J, Hetta J, Wiklund I, Erfurth E, Hägg E \& Karlsson F. Quality of life in adults with growth hormone (GH) deficiency: response to treatment with recombinant human GH in a placebo-controlled 21-month trial. Journal of Clinical Endocrinology and Metabolism 199580 3585-3590. (doi:10.1210/ jcem.80.12.8530603)

11 Attanasio A, Lamberts S, Matranga A, Birkett M, Bates P, Valk N, Hilsted J, Bengtsson B- $\AA$ \& Strasburger C. Adult growth hormone (GH)-deficient patients demonstrate heterogeneity between childhood onset and adult onset before and during human GH treatment. Journal of Clinical Endocrinology and Metabolism 199782 82-88. (doi:10.1210/jc.82.1.82)

12 Baum H, Katznelson L, Sherman J, Biller B, Hayden D, Schoenfeld D, Cannistraro K \& Klibanski A. Effects of physiological growth hormone (GH) therapy on cognition and quality of life in patients with adultonset GH deficit. Journal of Clinical Endocrinology and Metabolism 1998 83 3184-3189. (doi:10.1210/jc.83.9.3184)

13 Deijen J, Arwert L, Witlox J \& Drent M. Differential effect sizes of growth hormone replacement on Quality of Life, wellbeing and health status in growth hormone deficient patients: a meta-analysis. Health and Quality of Life Outcomes 20053 63. (doi:10.1186/14777525-3-63)

14 Hazem A, Elamin M, Bancos I, Malaga G, Prutsky G, Domecq J, Elraiyah T, Abu Elnour N, Prevost Y, Almandoz J et al. Body composition and quality of life in adults treated with GH therapy: a systematic review and meta-analysis. European Journal of Endocrinology 2012166 13-20. (doi:10.1530/EJE-11-0558)

15 Svensson J, Finer N, Bouloux P, Bevan J, Jonsson B, Mattsson A, Lundberg M, Harris P, Koltowska-Häggström M \& Monson J. Growth hormone $(\mathrm{GH})$ replacement therapy in $\mathrm{GH}$ deficient adults: predictors of one-year metabolic and clinical response. Growth Hormone and IGF Research 200717 67-76. (doi:10.1016/j. ghir.2006.11.002)

16 Mo D, Blum W, Rosilio M, Webb S, Qi R \& Strasburger C. Ten-year change in quality of life in adults on growth hormone replacement for growth hormone deficiency: an analysis of the hypopituitary control and complications study. Journal of Clinical Endocrinology and Metabolism 201499 4581-4588. (doi:10.1210/ jc.2014-2892)

17 Wirén L, Bengtsson B-Å \& Johannsson G. Beneficial effects of longterm GH replacement therapy on quality of life in adults with GH deficiency. Clinical Endocrinology 199848 613-620. (doi:10.1046/ j.1365-2265.1998.00462.x)

18 Gibney J, Wallace J, Spinks T, Schnorr L, Ranicar A, Cuneo R, Lockhart S, Burnard K, Salomon F, Sonksen P et al. The effects of 10 years of recombinant human growth hormone $(\mathrm{GH})$ in adult GH-deficient patients. Journal of Clinical Endocrinology and Metabolism 199984 2596-2602. (doi:10.1210/jcem.84.8.5916)

19 Gilchrist F, Murray R \& Shalet S. The effect of long-term untreated growth hormone deficiency (GHD) and 9 years of GH replacement on the quality of life (QoL) of GH-deficient adults. Clinical Endocrinology 200257 363-370. (doi:10.1046/j.1365-2265.2002.01608.x)

20 Kołtowska-Häggström M, Mattsson A, Monson J, Kind P, Badia X, Casanueva F, Busschbach J, Koppeschaar H \& Johannsson G. Does long-term GH replacement therapy in hypopituitary adults with GH deficiency normalise quality of life? European Journal of Endocrinology 2006155 109-119. (doi:10.1530/eje.1.02176)

21 Spielhagen C, Schwahn C, Möller K, Friedrich N, Kohlmann T, Moock J, Kołtowska-Häggström M, Nauck M, Buchfelder M \& Wallaschofski $\mathrm{H}$. The benefit of long-term growth hormone $(\mathrm{GH})$ replacement therapy in hypopituitary adults with GH deficiency: results of the German KIMS database. Growth Hormone and IGF Research 201121 1-10. (doi:10.1016/j.ghir.2010.10.005)

22 Rosilio M, Blum W, Edwards D, Shavrikova E, Valle D, Lamberts S, Erfurth E, Webb S, Ross R, Chihara K et al. Long-term improvement of quality of life during growth hormone $(\mathrm{GH})$ replacement therapy in adults with GH deficiency, as measured by questions on life satisfaction-hypopituitarism (QLS-H). Journal of Clinical 
Endocrinology and Metabolism 200489 1684-1693. (doi:10.1210/ jc.2003-030134)

23 Appelman-Dijkstra N, Claessen K, Roelfsema F, Pereira A \& Biermasz N. Long-term effects of recombinant human GH replacement in adults with GH deficiency: a systematic review. European Journal of Endocrinology 2013169 R1-R14. (doi:10.1530/EJE12-1088)

24 Boland E. Antirheumatic effects of hydrocortisone (free alcohol), hydrocortisone acetate, and cortisone (free alcohol) as compared with cortisone acetate; results from oral administration in patients with rheumatoid arthritis. British Medical Journal 19521 559-564. (doi:10.1136/bmj.1.4758.559)

25 Dupuy H. The psychological general well-being (PGWB) index. In Assessment of Quality of Life in Clinical Trials of Cardiovascular Therapies, pp 170-183. Eds N Wenger, M Mattson, C Furberg \& J Elinson. New York, NY, USA: Le Jacq Publications, 1984.

26 Doward L. The development of the AGHDA: a measure to assess quality of life in adults with growth hormone deficiency. Quality of Life Research 19954 420-421.

27 Holmes S \& Shalet S. Development of a questionnaire to assess the quality of life in adults with growth hormone deficiency. Endocrinology and Metabolism 19952 63-69.

28 McKenna S, Doward L, Alonso J, Kohlmann T, Niero M, Prieto L \& Wirén L. The QoL-AGHDA: an instrument for the assessment of quality of life in adults with growth hormone deficiency. Quality of Life Research 19998 373-383. (doi:10.1023/A:1008987922774)

29 Svensson J, Mattsson A, Rosén T, Wirén L, Johansson G, Bengtsson B- $\AA$ \& Koltowska Häggström M. Three-years of GH replacement therapy in GH-deficient adults: Effects on quality of life, patient-reported outcomes and healthcare consumption. Growth Hormone and IGF Research 200414 207-215. (doi:10.1016/j.ghir.2003.12.001)
30 Saller B, Mattsson A, Kann P, Koppeschaar H, Svensson J, Pompen M \& Koltowska-Häggström M. Healthcare utilization, quality of life and patient-reported outcomes during two years of GH replacement therapy in GH-deficient adults - comparison between Sweden, The Netherlands and Germany. European Journal of Endocrinology $2006 \mathbf{1 5 4}$ 843-850. (doi:10.1530/eje.1.02149)

31 Brabant G, von zur Mühlen A, Wüster C, Ranke M, Kratzsch J, Kiess W, Ketelslegers J, Wilhelmsen L, Hulthén L, Saller B et al. Serum insulin-like growth factor I reference values for an automated chemiluminescence immunoassay system: results from a multicenter study. Hormone Research 200360 53-60. (doi:10.1159/000071871)

32 Landin-Wilhelmsen K, Wilhelmsen L, Lappas G, Rosén T, Lindstedt G, Lundberg P-A \& Bengtsson B-Å. Serum insulinlike growth factor I in a random population sample of men and women: relation to age, sex, smoking habits, coffee consumption and physical activity, blood pressure and concentrations of plasma lipids, fibrinogen, parathyroid hormone and osteocalcin. Clinical Endocrinology 199441 351-357. (doi:10.1111/j.1365-2265.1994. tb02556.x)

33 Svensson J, Johannsson G \& Bengtsson B-Å. Insulin-like growth factor-I in growth hormone-deficient adults: relationship to population-based normal values, body composition and insulin tolerance test. Clinical Endocrinology 199746 579-586. (doi:10.1046/ j.1365-2265.1997.1851001.x)

34 Cohen J. A power primer. Psychological Bulletin 1992112 155-159. (doi:10.1037/0033-2909.112.1.155)

35 Koltowska-Häggström M, Mattsson A \& Shalet S. Assessment of quality of life in adult patients with GH deficiency: KIMS contribution to clinical practice and pharmacoeconomic evaluations. European Journal of Endocrinology 2009161 (Supplement 1) S51-S64. (doi:10.1530/eje-09-0266)

Received 21 October 2016

Accepted 1 November 2016 